\section{P15 EXPOSURE TO PM 2.5 IN EARLY PREGNANCY WAS ASSOCIATED WITH ABNORMAL CORD INSERTION IN A JAPANESE PREGNANT POPULATION}

${ }^{1}$ Takehiro Michikawa* ${ }^{2}$ Seiichi Morokuma, ${ }^{1}$ Yuki Takeda, ${ }^{3}$ Shin Yamazak ${ }^{4}$ Kazushige Nakahara, ${ }^{3}$ Akinori Takami, ${ }^{3}$ Ayako Yoshino, ${ }^{3}$ Seiji Sugata, ${ }^{5}$ Shinji Saito, ${ }^{5}$ Junya Hoshi. 'Department of Environmental and Occupational Health, School of Medicine, Toho University, Tokyo, Japan; ' 2 Department of Health Sciences, Graduate School of Medical Sciences, Kyushu University, Fukuoka, Japan; ${ }^{3}$ National Institute for Environmental Studies, Tsukuba, Japan; ${ }^{4}$ Department of Obstetrics and Gynaecology, Graduate School of Medical Sciences, Kyushu University, Fukuoka, Japan; ${ }^{5}$ Tokyo Metropolitan Research Institute for Environmental Protection, Tokyo, Japan

\subsection{6/jech-2021-SSMabstracts. 105}

Background Fine particulate matter $\left(\mathrm{PM}_{2.5}\right)$ is not an established, but a strongly suspected risk factor in the occurrence of adverse maternal and foetus outcomes. Currently, the researchers have an interest in the critical time window for maternal exposure to $\mathrm{PM}_{2.5}$, and maternal and foetus health. Although exposure to $\mathrm{PM}_{2.5}$ is likely to have adverse effects from the early pregnancy, including the period of implantation, there is not enough evidence. To evaluate the effects of $\mathrm{PM}_{2.5}$ exposure and its components in the early pregnancy, we used abnormal cord insertion, which is one of placental implantation abnormalities, as an outcome, and examined the $\mathrm{PM}_{2.5}$-cord insertion association.

Methods Data on 83,454 mothers who delivered singleton births at 39 cooperating hospitals between 2013 and 2015 in 23 Tokyo wards was obtained from the Japan Perinatal Registry Network database, which was managed by the Japan Society of Obstetrics and Gynaecology. At one central monitoring site, fine particle was collected on a filter each day, and carbon and ion components of $\mathrm{PM}_{2.5}$ were analysed. The period of the first trimester (0-13 gestational weeks) was estimated to each woman, and the average concentrations in that period were calculated by the daily measurement of $\mathrm{PM}_{2.5}$ and its components. Abnormal cord insertion was defined as velamentous and marginal cord insertion. The odds ratios (ORs) of abnormal cord insertion were estimated using multi-level logistic regression analysis.

Results In this population, the mean age at delivery was 33.7 years, and the proportion of abnormal cord insertion accounted for $4.5 \%$. The median concentration of total $\mathrm{PM}_{2.5}$ over the first trimester was 16.1 (interquartile range (IQR) = 3.6) $\mu \mathrm{g} / \mathrm{m}^{3}$. Exposure to total $\mathrm{PM}_{2.5}$ was associated with abnormal cord insertion (OR per IQR $=1.09$, 95\% CI = 1.02-1.16). In the multi-component model, organic carbon was only component that increased the odds of abnormal cord insertion in a consistent manner. In addition, exposure to organic carbon over the first month of pregnancy (implantation period) was clearly associated with outcome.

Conclusion The findings in this study supported our hypothesis that exposure to $\mathrm{PM}_{2.5}$ has unfavourable effects from the early pregnancy.

\section{P16 KNOWLEDGE, ATTITUDE AND PRACTICE OF COMPLEMENTARY FEEDING AMONG MOTHERS OF CHILDREN AGED 6 TO 24 MONTHS IN MUSHIN LOCAL GOVERNMENT, LAGOS, NIGERIA}

Christiana Ogunlana*. Medicine and Surgery, University of Lagos, Lagos, Nigeria

10.1136/jech-2021-SSMabstracts. 106
Background It is well recognised that the period between birth and 2 years of age is a critical window to promote health and development, and prevent stunting. In most countries, the majority of the decline in length-for-age during the first 2 years of life occurs during the complementary feeding period, between 6 and 24 months of age. Prevalence of optimal complementary feeding practices are lower than expected. Undernutrition contributes $35 \%$ of child mortality. Poor complementary feeding of children aged 6 to 24 months contributes to the characteristic negative trends and deaths observed in developing countries.

Methods This is a community-based cross-sectional descriptive study using a semi-structured questionnaire which was interviewer-administered to 380 mothers of children aged 6 to 24 months in the community. Multi-stage sampling was used to select the study participants. Epi-info version 7 was used to analyse the data.

Results Of the mothers interviewed, $50.79 \%$ of them reported good knowledge; $66.84 \%$ had good attitude and only $25.26 \%$ had good practice of complementary feeding. The significant factors affecting complementary feeding practice were mothers' educational status ( $\mathrm{p}$-value $=0.0005)$; antenatal clinic visits (pvalue $=0.0006)$; and household monthly income ( $\mathrm{p}$-value $=0.0000)$ Conclusion The results of this study indicate that complementary feeding practices are suboptimal in Mushin local government of Lagos, Nigeria. In addition, there is knowledgepractice gap among the mothers owing to factors such as mothers' educational status, household income and antenatal clinic visits.

\section{P17 CORRELATES OF IMMUNISATION STATUS OF CHILDREN UNDER FIVE IN BADAGRY LOCAL GOVERNMENT AREA, LAGOS, NIGERIA}

Adetola Toye*, Alero Roberts. Department of Community Health and Primary Care, College of Medicine, University of Lagos (CMUL), Lagos, Nigeria

\subsection{6/jech-2021-SSMabstracts. 107}

Background Despite the success and cost-effectiveness of immunisation in preventing infectious diseases, vaccine preventable diseases still contribute to child mortality in Africa. Results from the Nigeria Demographic and Health Survey suggest a low coverage of childhood immunisation reporting only $31 \%$ of Nigerian children who have received all basic vaccinations. This study aimed to determine the immunisation status of children under five, and significantly associated correlates regarding childhood immunisation and timeliness of vaccine uptake among these children in Badagry Local Government Area (LGA), Lagos, Nigeria.

Methods This descriptive cross-sectional study was conducted among 140 mothers of children under five residing in Badagry LGA, selected using multi-stage sampling. The main outcome was the child's immunisation status. Data was collected using KoBoToolbox and sought information about immunisation history and associated independent variables of parental age, educational level, occupation, household characteristics, antenatal and birth history. Analysis was done with Epi Info ver 7. Associations between independent and dependent variables were assessed using chi square test with level of significance set at $p<0.05$. Ethical approval was obtained from Lagos University Teaching Hospital Human Research Ethics Committee (LUTH-HREC). 
Results Majority (78.57\%) of children were fully immunised in a timely manner, $7.86 \%$ were fully immunised in an untimely manner, $10.71 \%$ were incompletely immunised for age and only 4 children were unvaccinated. Although aware of childhood immunisation, $63.57 \%$ of them had poor knowledge regarding childhood immunisation. Statistically significant associations were found between a child's immunisation status and maternal age $(p=0.0072)$, mother's highest educational level $(p=0.0000)$, her husband's age $(p=0.0001)$ and highest educational level $(p=0.0000)$, estimated household monthly income $(p=0.0292)$, number of siblings a child had $(p=0.0001)$, child's place of birth $(p=0.0000)$, antenatal care $(p=0.0000)$ and vaccination card availability $(p=0.0000)$.

Conclusion Badagry LGA is a major border town with heavy cross-border traffic facilitating transmission of diseases internationally. The gaps in immunization status of the children can be attributed to most mothers having poor overall knowledge. Parental age, educational level, estimated household income and household composition have significant impact on immunisation coverage and significantly, all unvaccinated children belonged to mothers with poor overall knowledge. Major limitations to this study were language barrier and unwillingness of mothers to be interviewed. This study demonstrates the need for continuous community engagement to improve immunisation completeness and timeliness of vaccine uptake.

\section{P18 KNOWLEDGE, PREVALENCE AND MANAGEMENT OF DOMESTIC ACCIDENTS IN MOTHERS OF CHILDREN UNDER FIVE IN MUSHIN SURBUBAN AREA, LAGOS, NIGERIA}

Sharon Ajudua*, Alero Roberts. Department of Community Health and Primary Care, College of Medicine, University of Lagos, Lagos, Nigeria

10.1136/jech-2021-SSMabstracts. 108

Background Domestic accidents are a major cause of death and undesirable incidents in children. It has adverse effects, health-wise and emotionally; even in the future. Moreover, the economic and social hub of Nigeria, Lagos state is lacking an evidence-based study on childhood domestic accidents. This study assessed knowledge on the types, causes and prevention; the prevalence of and management practices used in domestic accidents among mothers of children under five in Mushin Local Government, Lagos, Nigeria.

Methods A descriptive cross-sectional study was conducted among 326 mothers in Mushin Local Government, Lagos. The mothers were recruited using multistage sampling method. Data was collected using a semi-structured, pretested, interviewer-administered questionnaire through Kobo Toolbox software. It was analysed using Microsoft Excel 2016 and Epiinfo 7.2.3.0. Chi-squared test was applied to study associations between the variables. P-value less than 0.05 was considered significant.

Results Most mothers had poor knowledge on the types and causes of domestic accidents (73\%), 26\% of them had moderate knowledge while only $2 \%$ of them had good knowledge on this. Cuts/wounds (61.7\%) were the commonest type of domestic accidents occuring in the kitchen while falls were mostly recorded in the bedroom (60.1\%), bathroom (84.6\%) and the immediate surroundings $(73.3 \%)$. The prevalence of domestic accidents over the last six months before the study was $27.5 \%$, of which $45 \%$ were females and $43 \%$, males.
Falls (56.8\%) was the most prevalent accident. Accidents occurred mostly in the kitchen (35\%). Some of the mothers $(62 \%)$ used first aid at home while others (75\%) sought other forms of care including home treatment. Some mothers used potentially harmful remedies in management such as palm/ black oils, salt, toothpaste, sheabutter, honey, eggs, malt, milk etc., depending on the domestic accident encountered. Sixty (60) mothers managed the accidents appropriately (68.18\%) while twenty-eight (28) mothers managed them inappropriately $(31.81 \%)$. There was only one death $(1 \%)$ due to drowning and no recorded deformity. Only $9 \%$ of the mothers had good knowledge on preventive practices while 91\% of them had poor knowledge. A factor significantly associated with mother's knowledge on preventive practices was her level of knowledge on the types and causes of domestic accidents $(\mathrm{P}=0.0004)$

Conclusion This study demonstrates that the knowledge of mothers on domestic accidents was generally poor especially for their level of education and socioeconomic status. They, however, mostly had appropriate management practices. There should be health education programs on prevention and first aid workshops for the management of domestic accidents.

\section{P20 EVALUATING THE IMPACT OF PLANNING GUIDANCE ON THE FOOD ENVIRONMENT, HEALTH OUTCOMES, AND INEQUALITIES: A QUASI-EXPERIMENTAL ANALYSIS USING LONGITUDINAL DATA FOR A LOCAL AUTHORITY IN THE NORTH EAST OF ENGLAND}

${ }^{1}$ Huasheng Xiang* ${ }^{1}$ Viviana Albani, ${ }^{2}$ Nasima Akhter, ${ }^{1}$ Louis Goffe ${ }^{3}$ Amelia Lake, ${ }^{1}$ Heather Brown. ${ }^{1}$ Population Health Sciences Institute, Newcastle University, Newcastle upon Tyne, UK; ${ }^{2}$ Department of Anthropology, Durham University, Durham, UK; ${ }^{3}$ Centre for Public Health Research, Teesside University, Middlesbrough, UK

\subsection{6/jech-2021-SSMabstracts. 109}

Background In light of the Covid-19 pandemic, the government has prioritised reducing obesity rates. Many local authorities have employed planning guidance to manage the local food environment and promote a healthy environment. There is a lack of evidence on the effectiveness of this type of guidance on the food environment and subsequently health outcomes in particular inequalities. The primary aim of this paper is to examine the impact of planning guidance on the number and type of food outlets, health outcomes in particular obesity rates for children, and inequalities in these outcomes in a local authority in the North East of England. Gateshead implemented a blanket ban on all new takeaways in 2015.

Methods The datasets consist of yearly number and type of food outlets in Gateshead from the Food Standards Agency Food Hygiene Rating System, Index of Multiple Deprivation 2015/2019, population density from the Office for National Statistics, childhood obesity data from the National Child Measurement Programme, and type 2 diabetes and hypertension data from Public Health England. The data is merged and analysed at lower layer super output area level across 8 years from 2012-2019. We use fixed effects and difference in difference models to investigate the impact of planning guidance on the food environment in Gateshead. The control groups are the neighbouring local authorities where did not implement the guidance. A fixed effects model will be employed to test the relationship between the density of food 